\title{
Comparing the Diagnostic Accuracy of Clinical and Radiological Measures in Hand Soft-Tissue Masses
}

\author{
Salman A. Alzaidi ${ }^{1}$, Qutaiba N. Shah Mardan ${ }^{2}$, Abrar Alotaibi ${ }^{3}$, Mohamed Elmoursy ${ }^{4}$ \\ 1. Plastic and Reconstructive Surgery, King Faisal Medical Complex, Taif, SAU 2. Plastic and Reconstructive Surgery, \\ King Faisal Specialist Hospital and Research Centre, Riyadh, SAU 3. Otolaryngology - Head and Neck Surgery, King \\ Abdulaziz Specialist Hospital, Taif, SAU 4. Plastic and Reconstructive Surgery, ME Clinics, Alexandria, EGY
}

Corresponding author: Salman A. Alzaidi, slmnalzaidi@gmail.com

\section{Abstract}

\section{Introduction}

Imaging modalities are imperative to aid in diagnosing hand soft-tissue tumors. Limited insight is available into the diagnostic accuracy of history and physical examination in comparison to radiological diagnosis.

\section{Methods}

In this retrospective analysis, data of patients with hand soft-tissue tumors that were surgically treated and diagnosed through biopsy were extracted; taking this as a reference, the sensitivity, specificity and positive and negative predictive values and likelihood ratios of the clinical approach and radiological tools were contrasted against each other.

\section{Results}

Data of a total of 34 patients were revised in this study. With a mean age of 40.1 years, the most common anatomical area of the hand to be affected by the tumors was the index $(n=7,(18.9 \%)$; ganglion cysts were the most common tumor $(n=9,26.5 \%)$ and magnetic resonance imaging was the most commonly used imaging modality $(n=24,70.6 \%$ ). Clinical diagnosis scored a sensitivity and specificity of $44.4 \%$ and $100 \%$ in ganglion cysts and $62.5 \%$ and $86.2 \%$ in giant cell tumors in contrast to the sensitivity and specificity of $66.7 \%$ and $100 \%$ for ganglion cysts and $50 \%$ and $90 \%$ for giant cell tumors scored by radiological modalities.

\section{Conclusion}

Clinical diagnosis could be non-inferior to radiological diagnosis, yet radiological examination remains a valuable adjunct to clinical examination. Larger scale, prospective studies are required before generalizing our results.

Review began 12/01/2020 Review ended 12/12/2020 Published 12/18/2020

() Copyright 2020

Alzaidi et al. This is an open access article distributed under the terms of the Creative Commons Attribution License CC-BY 4.0., which permits unrestricted use, distribution, and reproduction in any medium, provided the original author and source are credited.
Categories: Plastic Surgery, Radiology, Orthopedics

Keywords: clinical diagnosis, diagnostic accuracy, soft tissue masses, radiological diagnosis

\section{Introduction}

Despite representing only $2 \%$ of the total body surface area [1] and $1.2 \%$ of total body weight, hands account for $15 \%$ of all soft-tissue tumors [2]. Fortunately, $95 \%$ of these, excluding tumors arising from the skin, are benign [3]. Most tend to present early, occupying relatively superficial structures and rendering them readily visible and palpable. Thus, most of the hand tumors have a favorable prognosis. Malignant soft-tissue masses that originate from hands, however, are unique, comprising only $2 \%$ of all hand lesions $[4,5]$.

Ganglion cysts, giant cell tumor of tendon sheath (GCTTS), lipomas, nerve sheath tumors, glomus tumors, and hemangiomas are the most frequent hand soft-tissue tumors [6]. A ganglion cyst is encountered in about $70 \%$ of hand swelling cases, making it the most common [7]. A variety of modalities can be used to make a diagnosis, including high-resolution ultrasonography (USG) and magnetic resonance imaging (MRI), which are important methods [2]. USG shows the most potential to differentiate tumors from pseudotumors and for lesion characterization, based on its nature and relationships [8]. USG is inexpensive, and it can be performed quickly. Based on the high contrast and spatial resolution, MRI is the cornerstone when the nature of the lesion, enhancement pattern, and exact location are investigated [9].

This study aims to explore the efficacy of soft-tissue tumor diagnostic tools because studies that demonstrate the effectiveness and accuracy of such tools are scarce. Because of this gap in comparing the accuracy of clinical assessment to radiology that is used in making a diagnosis [10], this study, in accordance with Standards for Reporting Diagnostic accuracy studies (STARD) guidelines [11], aimed to study the 


\section{Cureus}

accuracy of clinically based diagnoses of soft-tissue masses in the hand.

\section{Materials And Methods}

In this retrospective analysis, data were gathered from the patients' files from November 2017 to February 2019. Ethics approval was obtained from the King Fahad Armed Forces Hospital ethics committee. The inclusion criteria were as follows: all patients presenting with soft-tissue masses in the hand to the plastic surgery clinic in King Fahad Armed Forces Hospital, Jeddah, Saudi Arabia, and who underwent surgery and had their diagnosis confirmed through histopathology. All patients who did not undergo surgery and/or whose diagnosis was not established through histopathology were excluded from this study. The data collected included the following demographic characteristics: age, gender, mass site, and location (right or left arm), and clinical, radiological, and histopathological diagnoses. Radiological and histopathological assessment was performed by radiology and pathology consultants.

The data were analyzed using SPSS version 25 (IBM Corp., Armonk, NY). Frequencies were calculated for all variables and measures of diagnosis accuracy were extrapolated. These included the following: sensitivity, specificity, positive predictive value, negative predictive value, positive likelihood ratio, and negative likelihood ratio.

\section{Results}

Data from 34 patients were accessed, and more than half of the participants $(67.6 \% ; \mathrm{n}=25)$ were women, while $32.4 \%(n=12)$ were men. The mean $( \pm S D)$ age of the study population was $40.1( \pm 15.5)$ years (range: 5 to 70 years). Study participants' demographic data are shown in Table 1 . The highest percentage of patients with soft-tissue swellings was observed in patients who were 21 to 45 years old. However, subjects aged 0 to 20 years had the lowest percentage.

\begin{tabular}{|c|c|c|}
\hline Parameter & Percentage, value & Measures of dispersion \\
\hline \multirow{3}{*}{ Age } & $0-20$ years of age $11.7 \%(n=4)$ & \multirow{3}{*}{$\mathrm{M}=40.5 \mathrm{SD}=14.4 ;$ Minimum $=5$, Maximum $=70$} \\
\hline & $21-45$ years of age $50 \%(n=17)$ & \\
\hline & $46-70$ years of age $38.2 \%(n=13)$ & \\
\hline \multirow{2}{*}{ Gender } & Males $35.3 \%(n=12)$ & - \\
\hline & Females $64.7 \%(n=22)$ & - \\
\hline Left-sided lesion & $50 \%(n=17)$ & - \\
\hline Right-sided lesion & $50 \%(n=17)$ & - \\
\hline
\end{tabular}

TABLE 1: Demographic data.

The distribution of lesions across the upper limbs is shown in Table 2. The lesions were located across the hand, most commonly in the index, thumb, and ring finger $(18.9 \%, n=7 ; 16.2 \%, n=6$; and $13.5 \%, n=5$, respectively). Additionally, $2.9 \%$ (two patients) of the observed lumps were located in the third metacarpal region. Both sides had an equal $(50 \%, \mathrm{n}=17)$ distribution in terms of dexterity or sinistrality. 


\section{Cureus}

\section{Site}

$2^{\text {nd }}$ digit

$1^{\text {st }}$ digit

$4^{\text {th }}$ digit

$3^{\text {rd }}$ digit

$5^{\text {th }}$ digit

Hand dorsum

Hand palm

Volar aspect of the wrist

Dorsal aspect of the wrist

$3^{\text {rd }}$ metacarpal area
Percentage, value

$20.5 \%(n=7)$

$17.6 \%(n=6)$

$14.7 \%(n=5)$

$8.8 \%(n=3)$

$8.8 \%(n=3)$

$8.8 \%(n=3)$

$5.8 \%(n=2)$

$5.8 \%(n=2)$

$5.8 \%(n=2)$

$2.9 \%(n=1)$

TABLE 2: Distribution of lesions across the upper limb.

As shown in Table 3, among the different types of tumors that were diagnosed through histopathology, ganglion cysts were the most common $(26.5 \%, \mathrm{n}=9)$, followed by GCTTS $(23.5 \%, \mathrm{n}=8)$ and glomus tumors $(8.8 \%, \mathrm{n}=3)$.

\begin{tabular}{|c|c|}
\hline Diagnosis proven on histopathology & Percentage, value \\
\hline Ganglion cyst & $26.5 \%(n=9)$ \\
\hline Giant cell tumor & $23.5 \%(n=8)$ \\
\hline Glomus tumor & $8.8 \%(n=3)$ \\
\hline Lipoma & $5.8 \%(n=2)$ \\
\hline Traumatic neuroma & $5.8 \%(n=2)$ \\
\hline Schwannoma & $5.8 \%(n=2)$ \\
\hline Calcified aponeurotic fibroma & $2.9 \%(n=1)$ \\
\hline Chronic synovitis & $2.9 \%(n=1)$ \\
\hline Fibroma & $2.9 \%(n=1)$ \\
\hline Angiomyoma & $2.9 \%(n=1)$ \\
\hline Myoblastoma & $2.9 \%(n=1)$ \\
\hline
\end{tabular}

\section{TABLE 3: Prevalence of different types of tumors diagnosed through histopathology.}

Note: Three cases have been excluded, as there was no available data about diagnosis through histopathology.

Different radiographic modalities were used preoperatively, including MRI in $70.6 \%$ of the patients $(n=24)$, USG in $14.7 \%(n=5)$, X-ray in $5.9 \%(n=2)$, and bone scan for $2.9 \%(n=1)$. The sensitivity of clinical examination of the ganglion cyst was $44.4 \%$, while the specificity reached $100 \%$. Clinical examination showed $62.5 \%$ sensitivity and $86.2 \%$ specificity for giant cell tumors. Imaging modalities, overall, showed $66.7 \%$ sensitivity and $100 \%$ specificity for ganglion cysts. For GCTTS, imaging techniques scored $50 \%$ in sensitivity and close to $90 \%$ in specificity. For MRI, which was the most frequently used imaging modality in this population, the sensitivity and specificity were both $100 \%$ for ganglion cysts. However, MRI showed 
66.7\% sensitivity and $85.7 \%$ specificity for giant cell tumors. For USG, the sensitivity and specificity were both $100 \%$ for ganglion cysts and GCTTS. Further details are shown in Table 4.

\begin{tabular}{|c|c|c|}
\hline \multirow{5}{*}{ Ultrasound } & Ganglion cyst & Giant cell tumor \\
\hline & $P P V=100 \%$ & $P P V=100 \%$ \\
\hline & $N P P=100 \%$ & NPP $=100 \%$ \\
\hline & $+\mathrm{LR}=0$ & $+\mathrm{LR}=0$ \\
\hline & $-L R=0$ & $-\mathrm{LR}=0$ \\
\hline \multirow{4}{*}{ Magnetic resonance imaging } & $P P V=100 \%$ & $P P V=57.1 \%$ \\
\hline & $N P P=100 \%$ & $\mathrm{NPP}=90 \%$ \\
\hline & $+\mathrm{LR}=0$ & $+\mathrm{LR}=4.4$ \\
\hline & $-L R=0$ & $-\mathrm{LR}=0.02$ \\
\hline
\end{tabular}

\section{TABLE 4: Ganglion cyst versus giant cell tumor}

PPV: Positive predictive value, NPP: negative predictive value, +LR: positive likelihood ratio and -LR: negative likelihood ratio of ultrasound and magnetic resonance imaging in the most two prevalent conditions in the study sample.

\section{Discussion}

It is important to clinically assess palpable hand lesions and have imaging guidance to assist in confirming the diagnosis. In a review involving 122 confirmed lipoma cases, physical examination alone was sufficient to obtain a correct diagnosis $85 \%$ of the time. Moreover, clinical diagnosis was found to match the accuracy of USG in diagnosing hand and wrist tumors, although it was not as good as MRI [12].

USG showed a sensitivity, specificity, and positive predictive value of $100 \%$ for ganglion cysts. USG was shown to be accurate in diagnosing ganglion cysts $75 \%$ of the time, but GCTTS was not as high, at 50\% [10].

MRI is widely considered to be the imaging technique of choice for characterizing and defining lesions to determine the best therapeutic plan. It was the most frequently used diagnostic modality in the current study. Our data suggest that MRI can accurately identify ganglion cysts, based on the $100 \%$ sensitivity, specificity, and positive predictive value. Similarly, albeit on a larger scale, McKeon et al. investigated the accuracy of the pre-operative MRI-based diagnosis of soft-tissue masses in the forearm, wrist, and hand [13]. After reviewing the records of 144 patients, they concluded that MRI was the most accurate test, especially with ganglion cyst cases, achieving a sensitivity of $94.7 \%$ and a specificity of $94.4 \%$. Overall, MRI had a sensitivity of $75 \%$ for soft-tissue tumors of the upper limb. For GCTTS, however, the situation is different. The sensitivity was limited to $66.7 \%$ and the specificity was higher, at $85.7 \%$. This wide variation in MRI accuracy among different hand soft-tissue tumors is not exclusive to our study [13]. A report on MRI accuracy in 20 patients with histologically proven benign peripheral nerve tumors showed a sensitivity of $75 \%$, with five out of the 20 MRIs suggesting another diagnosis [14]. Another study involving 42 patients with diagnosed glomus tumors who underwent MRI as part of their pre-operative work-up showed a sensitivity of $86 \%$ [15]. Thus, we can conclude that pre-operative MRI for soft-tissue masses in the hands is critical, provided that caution is taken not to blindly follow the pre-operative diagnosis that is suggested by MRI analysis alone. Clinical examination may miss early cases of glomus tumors, especially subungual tumors, and thus, a decision based on a combined clinical examination and MRI would be optimal [16].

Several factors limit the generalizability and conclusions that can be drawn based on this study. In addition to the retrospective nature of the study, the small sample size decreases the strength of the study. Furthermore, diagnoses based on clinical sense are highly subjective to inter-personal variation in knowledge and experience.

\section{Conclusions}

Relevant clinical examination plays an essential, and often overlooked, role, along with radiological investigations, in diagnosing hand soft-tissue tumors. Data in this study suggest that properly approaching a clinically based diagnosis of soft-tissue masses, specifically ganglion cyst and GCTTS, in the upper limbs could be non-inferior to making a diagnosis using imaging modalities. Until more conclusive data are 
available, the optimal practice should remain dependent on a combination of radiographic measures that are guided by clinical sense.

\section{Additional Information \\ Disclosures}

Human subjects: All authors have confirmed that this study did not involve human participants or tissue. Animal subjects: All authors have confirmed that this study did not involve animal subjects or tissue. Conflicts of interest: In compliance with the ICMJE uniform disclosure form, all authors declare the following: Payment/services info: All authors have declared that no financial support was received from any organization for the submitted work. Financial relationships: All authors have declared that they have no financial relationships at present or within the previous three years with any organizations that might have an interest in the submitted work. Other relationships: All authors have declared that there are no other relationships or activities that could appear to have influenced the submitted work.

\section{References}

1. Rhodes J, Clay C, Phillips M: The surface area of the hand and the palm for estimating percentage of total body surface area: results of a meta-analysis. Br J Dermatol. 2013, 169:76-84. 10.1111/bjd.12290

2. Garcia J, Bianchi S: Diagnostic imaging of tumors of the hand and wrist . Eur Radiol. 2001, 11:1470-1482. $10.1007 /$ s003300000751

3. Mavrogenis AF, Panagopoulos GN, Angelini A, et al.: Tumors of the hand Eur J Orthop Surg Traumatol. 2017, 27:747-762. 10.1007/s00590-017-1984-y

4. Johnson J, Kilgore E, Newmeyer W: Tumorous lesions of the hand. J Hand Surg. 1985, 10:284-286. 10.1016/s0363-5023(85)80124-6

5. Puhaindran ME, Athanasian EA: Malignant and metastatic tumors of the hand . J Hand Surg. 2010, 35:18951900. 10.1016/j.jhsa.2010.08.014

6. Hasham S, Burke FD: Diagnosis and treatment of swellings in the hand . Postgrad Med J. 2007, 83:296-300. 10.1136/pgmj.2005.043992

7. Angelides AC, Wallace PF: The dorsal ganglion of the wrist: its pathogenesis, gross and microscopic anatomy, and surgical treatment. J Hand Surg. 1976, 1:228-235. 10.1016/s0363-5023(76)80042-1

8. Cheng J-W, Tang SFT, Yu T-Y, Chou S-W, Wong AMK, Tsai W-C: Sonographic features of soft tissue tumors in the hand and forearm. Chang Gung Med J. 2007, 30:547-554.

9. Lee CH, Tandon A: Focal hand lesions: review and radiological approach . Insights Imaging. 2014, 5:301-319. 10.1007/s13244-014-0334-4

10. Plonczak AM, Niruttan K, Jain A: Should we be imaging soft tissue masses of the hand and wrist? . J Plast Reconstr Aesthet Surg. 2019, 72:335-354. 10.1016/j.bjps.2018.10.041

11. Cohen JF, Korevaar DA, Altman DG, et al.: STARD 2015 guidelines for reporting diagnostic accuracy studies: explanation and elaboration. BMJ Open. 2016, 6:e012799. 10.1136/bmjopen-2016-012799

12. Leffert R: Lipomas of the upper extremity. JBJS. 1972, 54:1262-1266.

13. McKeon K, Wright B, Lee D: Accuracy of MRI-based diagnoses for distal upper extremity soft tissue masses . J Hand Microsurg. 2015, 7:61-66. 10.1007/s12593-015-0174-6

14. Nilsson J, Sandberg K, Søe Nielsen N, Dahlin LB: Magnetic resonance imaging of peripheral nerve tumours in the upper extremity. Scand J Plast Reconstr Surg Hand Surg. 2009, 43:153-159. 10.1080/02844310902734572

15. Al-Qattan MM, Al-Namla A, Al-Thunayan A, Al-Subhi F, El-Shayeb AF: Magnetic resonance imaging in the diagnosis of glomus tumours of the hand. J Hand Surg. 2005, 30:535-540. 10.1016/j.jhsb.2005.06.009

16. Koç O, Kivrak A, Paksoy Y: Subungual glomus tumour: magnetic resonance imaging findings: subungual glomus tumour. Australas Radiol. 2007, 51:107-109. DOI: 10.1111/j.1440-1673.2007.01797.x 